\title{
Effects of Small Amounts of Phosphoric Acid as Additive in the Preparation of Microporous Activated Carbons
}

\author{
Guanfeng LIN ${ }^{1,2}$, Kaijin $\mathrm{WU}^{3}$, Biao HUANG ${ }^{2}$ * \\ ${ }^{1}$ Jinshan College of Fujian Agriculture and Forestry University, No.15 Shangxiadian Road, Cangshan District, Fuzhou \\ City, Fujian Province 350002, China \\ ${ }^{2}$ College of Materials Engineering, Fujian Agriculture and Forestry University, No.15 Shangxiadian Road, Cangshan \\ District, Fuzhou City, Fujian Province 350002, China \\ ${ }^{3}$ Fujian Academy of Forestry, No.35 Red BridgeVillage, Xindian Town, Fuzhou City, Fujian Province 35002, China
}

crossref http://dx.doi.org/10.5755/j01.ms.24.4.18999

Received 08 September 2017; accepted 18 December 2017

\begin{abstract}
The activated carbons with well-developed microporosity were prepared from fir wood (Cunninghamia lanceolata) impregnated with small amounts of phosphoric acid (impregnation ratios, $1.5-4.5 \mathrm{wt} \%$ ). For comparison purpose, a parallel study of fir wood without impregnation was carried out in the same conditions. The results showed that the addition of small amounts of $\mathrm{H}_{3} \mathrm{PO}_{4}$ could lower the thermal decomposition temperature of fir wood and significantly promote the adsorption capacity and the yield of activated carbon. The yield without phosphoric acid impregnation was $6.55 \mathrm{wt} \%$, which rose to $19.82 \mathrm{wt} . \%$ in the case of $3.0 \mathrm{wt} . \% \mathrm{H}_{3} \mathrm{PO}_{4}$ impregnation. Using small amounts of phosphoric acid as additive was beneficial to improve specific surface area $\left(S_{\mathrm{BET}}\right)$ and micropore volume $\left(V_{\mathrm{mic}}\right)$, and could produce activated carbons with well-developed microporous structure. With $3.0 \mathrm{wt} \% \mathrm{H}_{3} \mathrm{PO}_{4}$ impregnation, $S_{\mathrm{BET}}$ and $V_{\text {mic }}$ of the activated carbon reached as high as $1281.6 \mathrm{~m}^{2} / \mathrm{g}$ and $0.535 \mathrm{~mL} / \mathrm{g}$, the ratio of $V_{\text {mic }} / V_{\text {tot }}$ (total pore volume) was higher than $80 \%$.

Keywords: activated carbon, phosphoric acid, impregnation, microporous, adsorption.
\end{abstract}

\section{INTRODUCTION}

Activated carbon is an excellent adsorbent, with large specific surface area and well-developed porosity, which is widely used as a purification material to eliminate harmful substances in gas and liquid phase [1,2]. In the context of deteriorating environment, the demand for activated carbon is also increasing. Various carbonaceous materials are used to prepare activated carbon and some of the most commonly used are agricultural and forestry by-products $[3,4]$. Fir sawdust is one of the major forestry residues which are low-cost and renewable materials. The reuse of fir sawdust to prepare activated carbon will enlarge its application and help to deal with the problems of disposal of wastes.

The preparation of activated carbon is generally divided into two parts: physical activation and chemical activation $[5,6]$. In this work, we have attempted to prepare the activated carbons by the method of using small amounts of phosphoric acid (impregnation ratios lower than 5 wt.\%) as additive, which may alter the pyrolysis of fir wood. The main operation process is impregnating the fir wood with phosphoric acid aqueous solution, and then carbonizing and activating the impregnated samples at relatively high temperature in a single step in atmospheric atmosphere, which is different from physical activation and chemical activation. When comparing with physical activation, this method needs to add small amounts of phosphoric acid in the impregnation step and combine the carbonization and activation into a single step, not carbonization (at $400 \sim 850{ }^{\circ} \mathrm{C}$, sometimes reach $1000{ }^{\circ} \mathrm{C}$ )

\footnotetext{
${ }^{*}$ Corresponding author. Tel.: +86-591-88160598.
}

E-mail address: bhuang@fafu.edu.cn (B. Huang) first and activation (at $800 \sim 1000{ }^{\circ} \mathrm{C}$ ) later [7, 8], which improves char yield and decreases energy consumption. When comparing with chemical activation, taking phosphoric acid activation (the range of impregnation ratios are from 30 to $300 \mathrm{wt} . \%$, much higher than $5 \mathrm{wt} . \%$ ) $[9,10]$ for example, this method requires less chemical reagents, which reduces environmental pollution. Therefore, this is a recommended method to prepare activated carbons which can overcome some disadvantages of physical activation and chemical activation.

There are some papers $[11-14]$ mentioning the effects of phosphoric acid as an additive (impregnation ratios $5 \sim 15 \mathrm{wt} . \%$ ) in the preparation of activated carbon fibers by $\mathrm{CO}_{2}$ activation from Nomex aramid fibers and poly(pphenylene benzobisoxazole). However, few articles report the preparation of activated carbon from lignocellulosic materials by the addition of such small amounts of phosphoric acid. In this paper, China fir wood (Cunninghamia lanceolata) was used as raw material to prepare activated carbons by the addition of phosphoric acid, and the impregnation ratios were from 1.5 to 4.5 wt.\%.

The main objective of this work is to elucidate the beneficial effects of small amounts of phosphoric acid added as an activator when preparing activated carbons from fir wood. The effects of different amounts (1.5, 3.0 and $4.5 \mathrm{wt} . \%$ ) of phosphoric acid on the porosity of the resulting activated carbons had been investigated, and the product without phosphoric acid impregnation in the same conditions was used to compare. The properties of impregnated samples and activated carbons were characterized by thermogravimetry and $\mathrm{N}_{2}$ adsorptiondesorption isotherms. 


\section{EXPERIMENTAL DETAILS}

China fir wood (Cunninghamia lanceolata) was used as raw material. Firstly, fir wood was crushed and sieved to get the size of 0.2 to $1 \mathrm{~mm}$ particles. The obtained material was stored in sealed containers for experimentation.

The preparation of activated carbon was performed as follow: a) the dried fir wood about $10 \mathrm{~g}$ was impregnated with $30 \mathrm{ml} \quad \mathrm{H}_{3} \mathrm{PO}_{4}$ aqueous solution of various concentrations: $0.5 \mathrm{wt} . \%, 1.0 \mathrm{wt} . \%$ and $1.5 \mathrm{wt} . \%$, to obtain impregnation ratios (Xp) of $1.5 \mathrm{wt} . \%, 3.0 \mathrm{wt} . \%$ and 4.5 wt.\%. Xp represents grams of phosphoric acid per gram of fir wood; b) the impregnation samples were heated at $120^{\circ} \mathrm{C}$ for $6 \mathrm{~h}$ in an oven; c) the samples were shifted into a $100 \mathrm{ml}$ ceramic crucible and then heated in a furnace (Nabertherm L9/11/SKM) from ambient temperature to $900{ }^{\circ} \mathrm{C}$ and resided in a flow of air $(3 \mathrm{ml} / \mathrm{min})$ for $4 \mathrm{~h}$; after the temperature in the furnace cooled down to room temperature, $0.1 \mathrm{M}$ hydrochloric acid and warm distilled water $\left(100^{\circ} \mathrm{C}\right)$ was used to washed the product until $\mathrm{pH}=6-7 ; \mathrm{d})$ at the end of the process, the samples were dried for $12 \mathrm{~h}$ in an oven at the temperature up to $110^{\circ} \mathrm{C}$. The activated carbon samples were produced and weighted to determine their yields. The impregnated samples were designated as F1.5, F3.0 and F4.5 respectively. F means fir wood, and the figures represent the impregnation ratios of phosphoric acid. The activated carbon samples were labelled as AC-X, which AC meant activated carbon and the figures $(1.5,3.0$ and 4.5) meant the impregnation ratios of H3PO4. To describe the effects of phosphoric acid additive, the product (without phosphoric acid impregnation, labelled as AC-0) was used to compare as well.

The analysis of adsorption of iodine value was carried out by D4607 test standards (ASTM D 4607-94). The thermal behavior of fir wood with (F1.5, F3.0 and F4.5, and without $\mathrm{H}_{3} \mathrm{PO}_{4}$ impregnation were investigated by a computerized thermobalance (NETZSCH Co, STA 409C, Germany). The elemental composition of activated carbons was performed by a $\mathrm{CHN}-\mathrm{O}$ rapid elemental analysis apparatus (PE-2400, US). Phosphorus content of the activated carbons and metallic content of fir wood were determined by an Inductively Coupled Plasma Emission Spectrometer (Perkin-Elmer OPTIMA7000, US). Oxygen content was estimated by difference. A volumetric adsorption analyzer (Micromeritics Co., ASAP 2020, USA) was used to characterize the pore of activated carbons by nitrogen adsorption at $196{ }^{\circ} \mathrm{C}$.

\section{RESULTS AND DISCUSSION}

\subsection{Effect of impregnation ratio of phosphoric acid}

Fig. 1 shows the iodine value and yield of $\mathrm{AC}-\mathrm{X}$ and AC-0. As illustrated in Fig. 1, the iodine value of activated carbons prepared from phosphoric acid impregnation is higher than that of without phosphoric acid impregnation, and the iodine value grows with rising impregnation ratio from $1.5 \mathrm{wt} . \%$ to $3.0 \mathrm{wt} \%$, but reduces with rising impregnation ratio from $3.0 \mathrm{wt} . \%$ to $4.5 \mathrm{wt} . \%$. The results reveal that the addition of small amounts of phosphoric acid may boost the porosity in the activated carbons and lead to higher adsorption capacity.

As found in Fig. 1, the increasing phosphoric acid impregnation ratio leads to the rising yield of activated carbons, and the addition of phosphoric acid significantly promotes the char yield. For example, the char yield of AC-3.0 (19.82 wt.\%) is significantly higher than AC-0 (6.55 wt.\%), more than 3 times. It also implies that the addition of small amounts of phosphoric acid may boost the yield of activated carbon. The reason is that phosphoric acid can dehydrate biopolymers during heat treatment. In the process of heat treatment, $\mathrm{H}$ and $\mathrm{O}$ in the polymer release in the form of water molecules, which inhibits the formation of tar, thus increases the yield $[15,16]$. Besides, the increase of yield for the impregnated samples can be attributed to the formation of polyphosphate by phosphoric acid modification [17]. Suárez-García et al. [17] pointed out that adding phosphoric acid was beneficial to the yield increase.

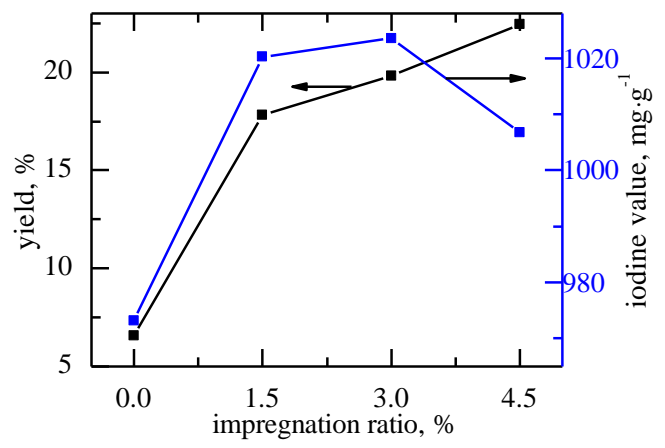

Fig. 1. Effect of impregnation ratio on iodine value and yield of activated carbon

\subsection{Thermal analysis}

The TG and DTG curves of fir wood with and without $\mathrm{H}_{3} \mathrm{PO}_{4}$ impregnation are shown in Fig. 2. There is moisture release at $50-140{ }^{\circ} \mathrm{C}$ in the case of phosphoric acid as additive. Then, a mass weight loss takes place from $140{ }^{\circ} \mathrm{C}$ up to around 320,310 and $290^{\circ} \mathrm{C}$ for F1.5, F3.0 and F4.5 with maximum weight loss rate at 290,271 and $261^{\circ} \mathrm{C}$ respectively (much lower than fir wood, $365^{\circ} \mathrm{C}$ ). It indicates the existence of small amount of phosphoric acid reduces the thermal decomposition temperature, the higher phosphoric acid impregnation ratio causes the lower thermal decomposition temperature. Such phenomenon conforms to the previous studies of the thermal decomposition on PPTA and PMIA with small amounts of $\mathrm{H}_{3} \mathrm{PO}_{4}$ impregnation $[12,17]$. After these mass loss steps, a small continuous loss is observed up to $1000{ }^{\circ} \mathrm{C}$. The char yield at $1000{ }^{\circ} \mathrm{C}$ for $\mathrm{F} 1.5, \mathrm{~F} 3.0$ and $\mathrm{F} 4.5$ is $39.4 \%$, $40.0 \%$ and $41.4 \%$ respectively, which is significantly higher than that of fir wood $(27.9 \%)$. It suggests that the impregnation of small amounts of phosphoric acid benefits the increase of char yield.

\subsection{Ultimate analysis}

Table 1 shows the element content of AC-0 and AC-X. As Table 1 shows, the $\mathrm{P}, \mathrm{H}$ and $\mathrm{O}$ contents of $\mathrm{AC}-\mathrm{X}$ are higher than $\mathrm{AC}-0$, especially the oxygen content, which exhibits a significantly higher increase. 


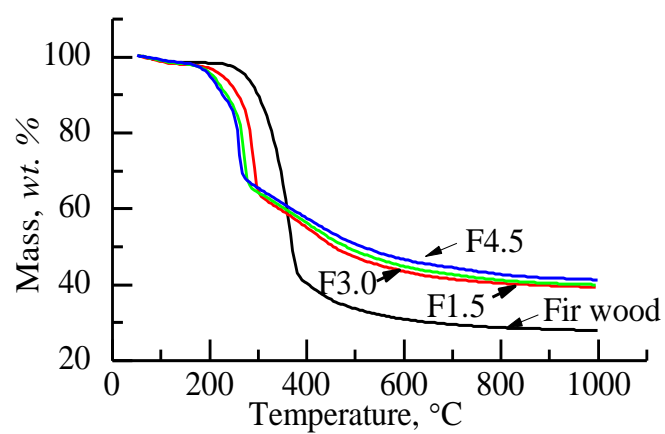

a

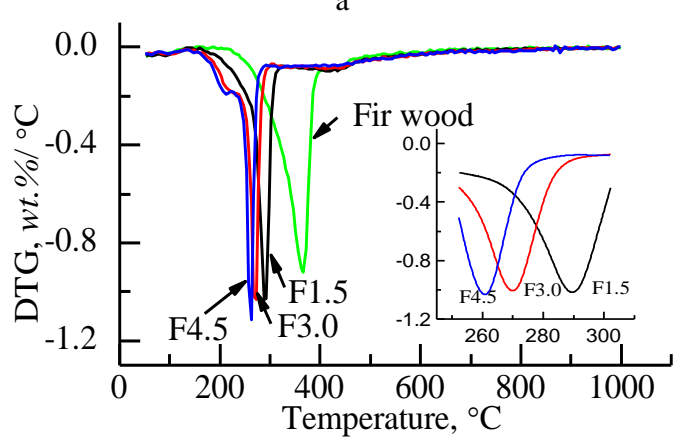

b

Fig. 2. TG (a) and DTG (b) curves for virgin and $\mathrm{H}_{3} \mathrm{PO}_{4}-$ impregnated fir wood

Table 1. Ultimate analysis

\begin{tabular}{|c|c|c|c|c|c|}
\hline Samples & $\mathrm{C}$ & $\mathrm{H}$ & $\mathrm{N}$ & $\mathrm{O}$ & $\mathrm{P}$ \\
\hline $\mathrm{AC}-0$ & 88.33 & 1.18 & 0.66 & 9.83 & -- \\
\hline $\mathrm{AC}-1.5$ & 87.19 & 1.21 & 0.60 & 11.00 & 0.10 \\
\hline AC-3.0 & 85.69 & 1.27 & 0.57 & 12.47 & 0.29 \\
\hline AC-4.5 & 84.75 & 1.42 & 0.70 & 13.13 & 0.39 \\
\hline
\end{tabular}

The $\mathrm{P}, \mathrm{H}$ and $\mathrm{O}$ contents increase with the increasing impregnation ratio, whereas the $\mathrm{C}$ content follows an opposite sense. And the research results agree with SuárezGarcía et al [13]. Moreover, the enhancement of oxygen content together with the presence of phosphorus that could not be eliminated by washing indicates that some $\mathrm{P}$ remains chemically bound to the activated carbons [11].

As impregnation ratio decreases, the atomic ratios of $\mathrm{H} / \mathrm{C}$ and $\mathrm{O} / \mathrm{C}$ decrease continuously from 0.017 and 0.16 in AC-4.5 to 0.014 and 0.13 in AC-1.5 respectively. According to the report of Sharma and Hajaligol, the decreases of the atomic ratios implies that activated carbons become more aromatic [18]. It is important to note that the atomic ratios of $\mathrm{H} / \mathrm{C}$ and $\mathrm{O} / \mathrm{C}$ in $\mathrm{AC}-0$ (0.013 and 0.11 ) are lower than those in $\mathrm{AC}-\mathrm{X}$. This phenomenon indicates that $\mathrm{AC}-0$ is more aromatic, and the presence of small amounts of phosphoric acid during pyrolysis inhibits the growth of aromatic rings.On the other hand, this phenomenon can also be proved by a small red shift from FT-IR curve (see supplementary file). Compared with
AC3.0, there is a small red shift for AC0, and the red shift indicates an enlargement of the aromatic ring system [19].

\subsection{Pore characteristics analysis}

The $\mathrm{N}_{2}$ adsorption-desorption isotherms of activated carbon produced with and without adding phosphoric acid is illustrated Fig. 3. The isotherms of activated carbon prepared with phosphoric acid as additive are type I, which reflects the predominance of microporosity. The almost overlap of adsorption isotherm and desorption isotherm proves the development of micropores too (The ratio of $V_{\text {mic }} / V_{\text {tot }}$ is $81.52,83.86$ and $85.21 \%$ respectively (Table 2)). And the presence of plateau isotherm indicates a minimum presence of mesopore structure [20]. The isotherm on AC-0 which prepared without phosphoric acid as additive is an isotherm intermediate between type I and type IV. It can be observed from the isotherm on AC-0, the curve with a larger opening, that microporosity develops significantly and even extends to mesoporosity. The shape of the hysteresis loop is intermediate between types $\mathrm{H} 3$ and $\mathrm{H} 4$, which reveals the presence of the slit-shaped pore and a wide distribution of pore sizes too [10]. A higher slope of the isotherm on $\mathrm{AC}-0$ at intermediate and high relative pressure indicates a certain span of pore sizes and a modest contribution from mesopores. As mentioned above, it can conclude that impregnation with phosphoric acid is beneficial to the development of micropores. The isotherms on AC-X are almost superposition, which implies the porosity of the activated carbons is hardly affected by the varied impregnation ratios of phosphoric acid.

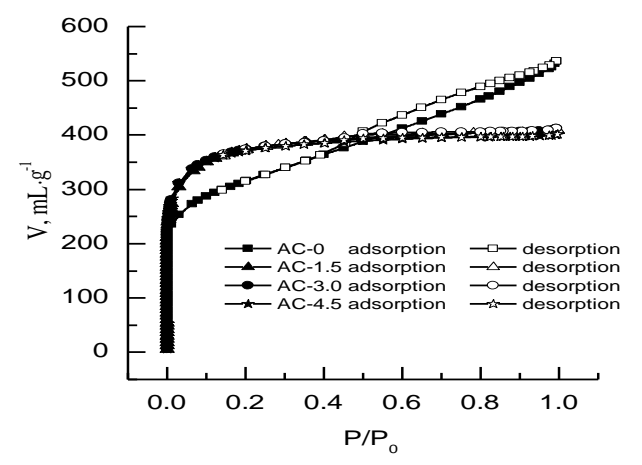

Fig. 3. $\mathrm{N}_{2}$ adsorption-desorption isotherms of activated carbon prepared with and without phosphoric acid as additive

As Table 2 shows, the specific surface area $\left(S_{\mathrm{BET}}\right)$ and the micropore volume $\left(V_{\text {mic }}\right)$ of AC-0 are lower than those of AC-X, whereas the total volume $\left(V_{\text {tot }}\right)$ and the mesopore volume $\left(V_{\mathrm{mes}}\right)$ show the opposite trend.

Table 2. Pore texture parameters derived from $\mathrm{N}_{2}$ adsorption isotherms of activated carbon prepared with and without phosphoric acid as additive

\begin{tabular}{|c|c|c|c|c|c|c|}
\hline Sample & $S_{\mathrm{BET}}, \mathrm{m}^{2} / \mathrm{g}$ & $V_{\text {tot }}, \mathrm{mL} / \mathrm{g}$ & $V_{\text {mic }}, \mathrm{mL} / \mathrm{g}$ & $V_{\text {mes }}, \mathrm{mL} / \mathrm{g}$ & $V_{\text {mic }} / V_{\text {tot }} \%$ & Average pore width, $\mathrm{nm}$ \\
\hline $\mathrm{AC}-0$ & 1094.0 & 0.829 & 0.453 & 0.376 & 54.64 & 3.03 \\
\hline $\mathrm{AC}-1.5$ & 1283.5 & 0.633 & 0.516 & 0.117 & 81.52 & 1.97 \\
\hline $\mathrm{AC}-3.0$ & 1281.6 & 0.638 & 0.535 & 0.103 & 83.86 & 1.99 \\
\hline $\mathrm{AC}-4.5$ & 1267.8 & 0.622 & 0.530 & 0.092 & 85.21 & 1.96 \\
\hline
\end{tabular}


The most possible reasons for the increasing $V_{\text {mic }}$ of $\mathrm{AC}-1.5, \mathrm{AC}-3.0$ and $\mathrm{AC}-4.5$ are that the volatilization of $\mathrm{P}-$ compounds promotes a new increase of porosity (mainly wider microporosity) and the contraction of the material after the release of $\mathrm{P}$-compounds produces the narrow microporosity [21].

However, the residual of phosphorus and phosphocarbonaceous compounds on AC-1.5, AC-3.0 and AC-4.5 may plug the porosity of the activated carbon, which leads to the decrease of $V_{\text {tot }}, V_{\text {mic }}$ and $V_{\text {mes. }}$ Although the residual of phosphorus and phosphocarbonaceous compounds plug the microporosity, the volatilization of $\mathrm{P}$ compounds produces more microporosity. Combining the effects of these two aspects, $V_{\text {mic }}$ still increase. Since AC-0 is prepared from fir wood without impregnation with phosphoric acid, it is not affected by these two aspects. Therefore, $\mathrm{V}_{\text {mic }}$ of AC-1.5, AC-3.0 and AC-4.5 is higher than $A C-0$, whereas $V_{\text {tot }}$ and $V_{\text {mes }}$ show the opposite trend.

The discrepancy of $\mathrm{S}_{\mathrm{BET}}, \mathrm{V}_{\text {tot }}, \mathrm{V}_{\text {mic }}$ and $\mathrm{V}_{\text {mes }}$ of AC-1.5, AC-3.0 and AC-4.5 is little (Table 2). It shows that the effect of different impregnation ratios on the pore structure is unobvious. Meanwhile, it is noteworthy that $V_{\text {mic }} / V_{\text {tot }}$ of $\mathrm{AC}-1.5, \mathrm{AC}-3.0$ and $\mathrm{AC}-4.5$ is higher than $80 \%$, and the average pore width is less than $2.0 \mathrm{~nm}$. Those suggest that impregnation with small amounts of phosphoric acid favors the development of micropores.

Fig. 4 displaces the pore size distributions (PSDs) of AC-0 and AC-3.0. Although both PSDs exhibit similar traces, an obvious change in two distinct regions still can be found: pore width less than $2 \mathrm{~nm}$ (micropore region) and in the range of $2-10 \mathrm{~nm}$ (mesopore region). For the former category, the volume of AC-3.0 is higher than AC0 . While the contribution of $2 \sim 10 \mathrm{~nm}$, the volume of AC3.0 is lower than AC- 0 . It indicates that $\mathrm{V}_{\text {mic }}$ of $\mathrm{AC}-3.0$ is higher than AC-0, but $\mathrm{V}_{\text {mes }}$ of AC-3.0 is lower than AC-0 (confirming to the analysis of Table 2). It is important to note that most of the pore width of AC-3.0 concentrates in the range of less than $2 \mathrm{~nm}$, which reveals that AC-3.0 is a well-developed microporosity product.

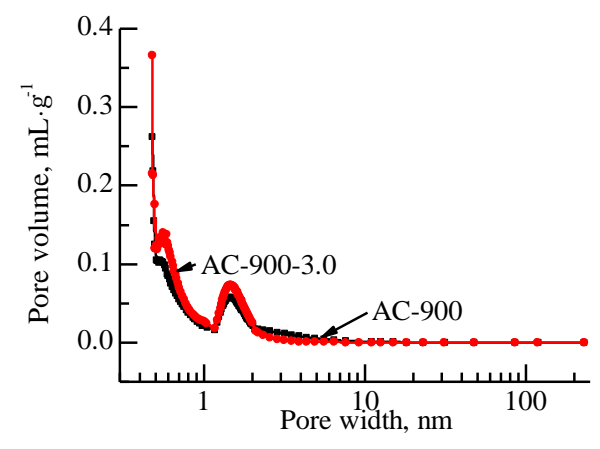

Fig. 4. PSDs calculated by DFT method on AC-0 and AC-3.0

\section{CONCLUSIONS}

The addition of small amounts of phosphoric acid has some beneficial effects on the pyrolysis of fir wood in air atmosphere at $900{ }^{\circ} \mathrm{C}$. The char yield obtained from samples impregnated with $1.5-4.5$ wt. $\% \mathrm{H}_{3} \mathrm{PO}_{4}$ increase greatly comparing with that of without $\mathrm{H}_{3} \mathrm{PO}_{4}$ impregnation. For example, the char yield of AC-1.5, AC-
3.0 and $\mathrm{AC}-4.5$ is $17.80,19.82$ and 22.44 wt.\%, much higher than that of AC-0 (6.55 wt.\%).

Small amounts of phosphoric acid as additive during pyrolysis can enhance the $\mathrm{O}, \mathrm{P}$ and $\mathrm{H}$ content, meanwhile reduce the $\mathrm{C}$ content of activated carbons.

Small amounts of phosphoric acid as additive during pyrolysis can lower the thermal decomposition temperature of fir wood and enhance the yield of activated carbons. The presence of small amounts of $\mathrm{H}_{3} \mathrm{PO}_{4}$ during pyrolysis is beneficial to the improvement of $\mathrm{S}_{\mathrm{BET}}$ and $V_{\text {mic }}$, and boost the development of microporosity. The $\mathrm{S}_{\mathrm{BET}}$ and $V_{\text {mic }}$ of AC-3.0 reach up to $1281.6 \mathrm{~m}^{2} / \mathrm{g}$ and $0.535 \mathrm{~mL} / \mathrm{g}$. The ratio of $V_{\text {mic }} / V_{\text {tot }}$ and the average pore width are $83.86 \%$ and $1.99 \mathrm{~nm}$ respectively, and the pore width concentrates in the range of less than $2 \mathrm{~nm}$.

Considering the yield, adsorption property, specific surface area and pore volume of activated carbon, the best impregnation ratio of phosphoric acid is $3.0 \mathrm{wt} . \%$. Therefore, the addition of small amounts of phosphoric acid is an available method to produce activated carbon with well-developed microporosity.

\section{Acknowledgments}

This work was supported by National Natural Science Foundation of China (31400510); Program for New Century Excellent Talents in Fujian Province University; Fujian Province outstanding youth scientific research personnel training program and Fujian Province young and middle-aged teacher education research project (JAT160684).

\section{REFERENCES}

1. Chen, C.X., Huang, B., Li, T., Wu, G. F. Preparation of Phosphoric Acid Activated Carbon from Sugarcane Biogases by Mechanochemical ProcessingBioResources 7 (4) 2012: pp. 5109-5116.

http://doi.org/10.15376/biores.7.4.5109-5116

2. Plaza-Recobert, M., Trautwein, G., Pérez-Cadenas, M., Alcañiz-Monge, J. Preparation of Binderless Activated Carbon Monoliths from Cocoa Bean Husk Microporous and Mesoporous Materials 243 2017: pp.28-38. https://doi.org/10.1016/j.micromeso.2017.02.015

3. Yorgun, S., Yıldız, D., Şimşek, Y.E. Activated Carbon from Paulownia Wood: Yields of Chemical Activation Stages Energy Sources Part A38 (14) 2016: pp. 2035-2042. http://doi.org/10.1080/15567036.2015.1030477

4. Zhang, S.P., Hu, B., Zhang, L., Xiong, Y.Q. Effects of Torrefaction on Yield and Quality of Pyrolysis Char and Its Application on Preparation of Activated Carbon Journal of Analytical and Applied Pyrolysis 119 2016: pp. $217-223$. http://doi.org/10.1016/j.jaap.2016.03.002

5. Ceyhan, A.A., Şahin, Ö., Baytar, O., Saka, C. Surface and Porous Characterization of Activated Carbon Prepared from Pyrolysis of Biomass by Two-stage Procedure at Low Activation Temperature and It's the Adsorption of Iodine Journal of Analytical and Applied Pyrolysis 104 2013: pp.378-383. http://doi.org/10.1016/j.jaap.2013.06.009

6. Sun, K., Jiang, J. Preparation and Characterization of Activated Carbon from Rubber-seed Shell by Physical 
Activation with Steam Biomass and Bioenergy 34 (4) 2010: pp. 539-544.

http://doi.org/10.1016/j.biombioe.2009.12.020

7. Klijanienko, A., Lorenc-Grabowska, E., Gryglewicz, G. Development of Mesoporosity during Phosphoric Acid Activation of Wood in Steam Atmosphere Bioresource Technology 99 (15) 2008: pp. 7208-7214. http://doi.org/10.1016/j.biortech.2007.12.059

8. Li, W., Yang, K., Peng, J., Zhang, L., Guo, S., Xia, H. Effects of Carbonization Temperatures on Characteristics of Porosity in Coconut Shell Chars and Activated Carbons Derived from Carbonized Coconut Shell Chars Industrial Crops and Products 28 (2) 2008: pp. 190-198.

http://doi.org/10.1016/j.indcrop.2008.02.012

9. Patnukao, P., Pavasant, P. Activated Carbon from Eucalyptus Camaldulensis DehnBark using Phosphoric Acid Activation Bioresource Technology 99 (17) 2008: pp. $8540-8543$. https://doi.org/10.1016/j.biortech.2006.10.049

10. Suarez-García, F., Martınez-Alonso, A., Tascon, J.M.D. Pyrolysis of Apple Pulp: Chemical Activation with Phosphoric Acid Journal of Analytical and Applied Pyrolysis 63 (2) 2002: pp. 283-301. https://doi.org/10.1016/S0165-2370(01)00160-7

11. Vázquez-Santos, M.B., Martínez-Alonso, A. Tascón, J.M.D. Effects of Phosphoric Acid as Additive in the Preparation of Activated Carbon Fibers from Poly(pphenylene benzobisoxazole) by Carbon Dioxide Activation Journal of Analytical and Applied Pyrolysis 95 2012: pp. $68-74$.

https://doi.org/10.1016/j.jaap.2012.01.007

12. Castro-Muñiz, A., Martínez-Alonso, A., Tascón, J.M.D. Effect of PPTA Pre-impregnation with Phosphoric Acid on the Porous Texture of Carbons Prepared by $\mathrm{CO}_{2}$ Activation of PPTA Chars Microporous and Mesoporous Materials $119(1-3)$ 2009: pp. 284-289.

https://doi.org/10.1016/j.micromeso.2008.10.025

13. Suárez-García, F., Martínez-Alonso, A., Tascón, J.M.D. Beneficial Effects of Phosphoric Acid as an Additive in the Preparation of Activated Carbon Fibers from Nomex Aramid Fibers by Physical Activation Fuel Processing Technology 77-78 2002: pp. 237-244. https://doi.org/10.1016/S0378-3820(02)00052-8
14. Suárez-García, F., Paredes, JI., Martínez-Alonso, A., Tascón, J.M.D. Preparation and Porous Texture Characteristics of Fibrous Ultrahigh Surface Area Carbons Journal of Materials Chemistry $12(11)$ 2002: pp. $3213-3219$. https://doi.org/10.1039/b204030a

15. Jagtoyen, M., Derbyshire, F. Activated Carbons from Yellow Poplar and White Oak by $\mathrm{H}_{3} \mathrm{PO}_{4}$ Activation Carbon 36 (7-8) 1998: pp. 1085-1097. https://doi.org/10.1016/S0008-6223(98)00082-7

16. Molina-Sabio, M., Rodríguez-Reinoso, F., Caturla, F., Sellés, M.J. Porosity in Granular Carbons Activated with Phosphoric Acid Carbon 33 (8) 1995: pp. 1105-1113. http://doi.org/10.1016/0008-6223(95)00059-M

17. Suárez-García, F., Villar-Rodil, S., Blanco, C.G., Martínez-Alonso, A., Tascón, J.M.D. Effect of Phosphoric Acid on Chemical Transformations during Nomex Pyrolysis Chemistry of Materials $16(13)$ 2004: pp. 2639-2647. https://doi.org/10.1021/cm0349654

18. Sharma, R.K., Hajaligol, M.R. Effect of Pyrolysis Conditions on the Formation of Polycyclic Aromatic Hydrocarbons (PAHs) from Polyphenolic Compounds Journal of Analytical and Applied Pyrolysis 66 2003:pp. 123-144. https://doi.org/10.1016/S0165-2370(02)00109-2

19. Puziy, A.M., Poddubnaya, O.I., Martínez-Alonso, A., Suarez-Garcia, F., Tascón, J.M.D. Synthetic Carbons Activated with Phosphoric Acid: I. Surface Chemistry and Ion Binding Properties Carbon 40 2002: pp. $1493-1505$. https://doi.org/10.1016/S0008-6223(01)00317-7

20. Lozano-Castello, D., Cazorla-Amorós, D., LinaresSolano, A., Quinn, D.F. Activated Carbon Monoliths for Methane Storage: Influence of Binder Carbon 40 (15) 2002: pp. $2817-2815$.

https://doi.org/10.1016/S0008-6223(02)00194-X

21. Suárez-García, F., Martínez-Alonso, A., Tascón, J.M.D. Nomex Polyaramid as a Precursor for Activated Carbon Fibres by Phosphoric Acid Activation. Temperature and Time Effects Microporous and Mesoporous Materials 75 (1-2) 2004: pp.73-80.

https://doi.org/10.1016/j.micromeso.2004.07.004 